\title{
LOS DOS CUERPOS MAYAS. ESBOZO DE UNA ANTROPOLOGÍA ELEMENTAL INDÍGENA
}

\author{
Pedro Pitarch \\ Universidad Complutense de Madrid
}

RESUMEN: El propósito de este artículo es llamar la atención sobre la distinción indígena maya de dos clases de cuerpos humanos: uno carnal compartido con los animales y uno fenoménico específico de los seres humanos. Esta distinción resulta a su vez análoga a las dos clases de almas indígenas: una con la forma del cuerpo y otra con figura no humana, generalmente de algún animal. Semejante paralelismo entre cuerpos y almas me lleva a proponer una reorganización del concepto de persona en términos de un modelo cuaternario. Éste, sin dejar de ser fundamentalmente binario (cuerpo/alma), debe permitir integrar elementos que, como los dos cuerpos por una parte, y las dos almas por otra, se distinguen tanto como se requieren mutuamente para llegar a constituir la persona.

Palabras clave: cuerpo, persona, ontología. tzeltales, mayas, Mesoamérica.

AвSTRACT: The purpose of this paper is to draw attention to the indigenous Maya distinction between two types of human bodies: a carnal body, shared with animals, and a specifically human phenomenic body. This distinction, in turn, is equivalent to the indigenous distinction between two souls: a soul in a human shape and a soul in a non-human shape, generally of an animal species. The parallelism between bodies and souls leads me to propose a reorganization of the Mesoamerican concept of person in terms of a quaternary model which remains essentially binary (body/soul), yet permits the integration of elements which are different to each other, like the two bodies and the two souls, and yet mutually necessary to make up the person.

KeYwords: body, personhood, Ontology, Tzeltal, Mayas, Mesoamerica.

ReCEPCIÓN: 2 de agosto del 2010.

ACEPTACIÓn: 11 de noviembre del 2010. 



\title{
LOS DOS CUERPOS MAYAS. ESBOZO DE UNA ANTROPOLOGÍA ELEMENTAL INDÍGENA
}

\author{
Pedro Pitarch \\ Universidad Complutense de Madrid
}

En este ensayo esbozo un modelo maya-tzeltal de persona sobre unas bases en parte distintas a las convencionalmente empleadas en la etnología mesoamericana. Lo que me indujo a desarrollarlo fue encontrar entre los indígenas tzeltales la distinción de dos clases de cuerpos en los humanos. Por una parte, un "cuerpocarne", unión de carne y fluidos que forman un conjunto segregable en partes, un objeto sensible pero sin capacidad de relación social con los demás seres, y que representa una cualidad substancialmente homogénea entre humanos y animales. Y por otra, un "cuerpo-presencia”: un sujeto activo de percepción, sentimiento y cognición, comprometido en una relación intersubjetiva con cuerpos de la misma especie. Semejante "disociación" del cuerpo resulta equivalente a lo que caracterizo como una distinción elemental de las almas mesoamericanas: una clase con la figura del cuerpo, y otra con forma no humana, generalmente de algún animal. Es precisamente esta homología entre cuerpos y almas lo que me lleva a proponer una modificación —una reorganización, si se prefiere- del concepto de persona indígena en términos de un modelo cuaternario compuesto por cuatro aspectos: una forma substancial (cuerpo-presencia), una substancia sin forma (cuerpo-carne), una forma insubstancial (alma-humana) y una insubstancialidad sin forma (alma-espíritu). Un modelo así, sin dejar de ser fundamentalmente binario (cuerpo/alma), posibilita, por una parte, integrar el esquema paralelo de dos cuerpos y dos almas que compone los seres humanos; a la vez cualifica las relaciones ontológicas de continuidad o discontinuidad de éstos con, de un lado, los animales y, de otro, los espíritus.

Como se ve, este trabajo puede considerarse como una contribución al campo de estudio de las "ontologías" amerindias desde el ángulo particular de la etnografía mesoamericana - un área poco representada, tanto desde un punto de vista empírico como conceptual, en las discusiones recientes sobre este tema-.

\footnotetext{
Presenté la primera parte del argumento de este artículo en el Centro de Estudios Mayas hace tres años y los comentarios de los asistentes me resultaron muy útiles; en este sentido agradezco especialmente a Martha Ilia Nájera y a Carmen Valverde. Gracias a Jérôme Baschet, Alfonso Lacadena, Peter Mason, Saúl Millán, Johannes Neurath, Perig Pitrou, Lydia Rodriguez, Alexandre Surrallés, AnneChristine Taylor, así como a dos comentaristas anónimos de la revista Estudios de Cultura Maya por sus observaciones clarificadoras sobre este ensayo.
} 
Es bien sabido que los estudios sobre antologías indígenas en la región amazónica (Descola, 2005; Taylor, 1996, 1998; Viveiros de Castro, 2002a), así como en el norte de América (Ingold, 1991), no solo están sirviendo de inspiración para estudios en otras regiones etnográficas (cf. Pedersen, 2001; Willerslev, 2007), sino que han cobrado una renovada presencia en la teoría antropológica contemporánea. Sin embargo, mi interés en este caso no es tanto la discusión aplicada a Mesoamérica de conceptos tales como animismo, totemismo, perspectivismo y otros análogos, sino, de forma más específica, la comprensión de las relaciones de continuidad y discontinuidad entre los principios corporales y espirituales de los seres. Una comprensión que, en todo caso, se encuentra en el fundamento mismo de la discusión sobre las ontologías amerindias (Viveiros de Castro, 2009: 48-49).

Pienso, en efecto, que para poder aprovechar estos conceptos en los estudios mesoamericanos debemos antes tratar de precisar mejor cuales son las relaciones entre cuerpo y alma y, todavía antes, qué es un "cuerpo" y qué es un "alma". De estos dos aspectos, el menos comprendido es, sin duda, el cuerpo. Hablando de modo general, en la etnografía mesoamericana el cuerpo ha tendido a ser visto como un objeto más bien natural y por tanto no necesariamente problemático en términos de su descripción cultural: si, por así decir, las almas pertenecen al campo de la variación cultural, el cuerpo, en cambio, forma parte del campo de los hechos objetivos. Conforme a esta convención, la etnografía de México y Guatemala ha detallado la presencia de una asombrosa pluralidad de almas (en parte como resultado del interés por el "nahualismo"), mientras el cuerpo ha sido considerado como un objeto singular. El estudio clásico de Alfredo López Austin (1980), que fundó los estudios sobre el físico en Mesoamérica y determinó su desarrollo ulterior, se ocupa principalmente de las partes anatómicas del cuerpo, de las almas, así como de las correspondencias entre estos aspectos y el resto del cosmos. Y, en efecto, con ciertas excepciones, ${ }^{1}$ en la etnografía mesoamericana contamos fundamentalmente con trabajos de etnoanatomía y su relación con el cosmos (cf. Romero López, 2006; Ruz, 1996; Stross, 1976; VillaRojas, 1980); o, en un sentido distinto, con estudios de linguística cognitiva que toman el cuerpo como objeto de descripción predilecta (cf. León, 1992; Levinson, 1994), posiblemente bajo la asunción de que se trata de un objeto común y por tanto más apto para la comparación linguística. En fin, los archivos de la etnografía mesoamericana contienen numerosos datos sobre cómo es el cuerpo indígena, pero muy poco sobre qué es un cuerpo indígena. Pero como ha destacado James Elkins (1986) a propósito de la disciplina del arte, para que pueda surgir el campo de los estudios del cuerpo debe producirse primero una devaluación del estudio académico de la anatomía.

\footnotetext{
${ }^{1}$ La principal es sin duda el estudio de Jacques Galinier (1990) sobre el cuerpo y la cosmología otomí. De un modo muy distinto - extrañamente distinto- al tzeltal, los otomíes dividen el cuerpo humano en mitades: una superior, solar, masculina, asociada con el mundo europeo y cristiano, y la otra inferior, femenina, lunar, asociada a la muerte y el sexo, así como a la cultura indígena.
} 
Este ensayo tiene un carácter más intensivo que extensivo. En lugar de fundarlo en un estudio comparativo con otros grupos indígenas de México y Guatemala, he preferido concentrarme en mis propios datos etnográficos tzeltales. La razón de esto es que no resulta fácil extrapolar los datos y distinciones que traigo aquí a otras etnografías escritas en función de preguntas diferentes, por no mencionar la naturaleza sumamente particularista de la etnografía mesoamericanista que tampoco facilita las generalizaciones comparativas. Así pues, más que comparaciones sistemáticas, trataré de hacer allí donde sea posible rápidas excursiones - consignándolas sobre todo en las notas a pie de página - tanto a otros grupos mayas como mesoamericanos de manera más amplia. Con todo, pienso probable que esta distinción de los dos cuerpos - y dos almas - sea algo relativamente extendido en las lenguas mesoamericanas.

\section{El "cuerpo-carne"}

Traduciré la palabra tzeltal bak'etal por “cuerpo-carne”. En un sentido literal, el término designa el "conjunto de la carne”, y su raíz — bak'et — significa "carne”, tanto carne humana como animal, carne tanto viva como un pedazo para ser comido. El vocabulario de la lengua tzeltal del siglo xvi del fraile Domingo de Ara (1986) traduce bak'etal como “cuerpo, carnal cosa”.

El cuerpo-carne comprende el conjunto del cuerpo humano, excepto los huesos, el cabello, el resto del vello corporal y las uñas. La razón de ello es que por estas partes no circula la sangre, y la sangre parece ser, en efecto, el elemento básico que define el cuerpo-carne. "La sangre da vida a la carne, si se corta la carne brota sangre"; el cuerpo-carne es "por donde circula la sangre, donde se recibe el aire, donde respira [la carne]”. Las ideas indígenas acerca del funcionamiento interno del cuerpo son sumamente imprecisas, pero prevalece la idea de que los sistemas sanguíneo y respiratorio constituyen uno solo. El corazón/ estómago recibe directamente el aire inspirado (indispensable para vivir) y el alimento, que proporciona la fuerza al cuerpo, y de aquí pasa al resto de él a través de la sangre. Por supuesto, ni los huesos, ni el pelo ni las uñas son recorridas por la sangre. "Si se cortan no duele". El dolor asociado al derramamiento de sangre es otra de las características de este cuerpo-carne. La carne duele si es cortada o abierta en una herida; duelen las extremidades, la cabeza, las articulaciones, las vísceras. Como parte de este cuerpo-carne suelen nombrarse cosas como los músculos, la grasa, las venas, la piel, la cabeza, las orejas, las extremidades, etc. De hecho, como veremos más adelante, una de las características del cuerpocarne es estar formado por "partes", fragmentos discretos claramente distinguibles y susceptibles de ser dañados por ciertos enemigos.

Para los tzeltales resulta evidente que los vegetales no tienen un cuerpocarne, pues las plantas, los árboles "no tienen sangre, no respiran". En cambio, todos los animales — terrestres, acuáticos, aves — sí poseen uno. Como sucede 
entre los humanos, ni pelaje, huesos, garras, plumas o picos forman parte de este cuerpo. Es cierto que entre los animales, a diferencia de lo que sucede entre los humanos, estos "adornos" pueden representar una fracción considerable del total del cuerpo, pero esto no resulta en una modificación de su apariencia porque en realidad el cuerpo-carne no proporciona una forma concreta a cada individuo. Lo que define a aquel no es la forma, sino la substancia de la que está compuesto. Un sinónimo de este cuerpo — kojtol— remite precisamente a este aspecto. Deriva del verbo kojt, que significa estar "a cuatro patas", en posición cuadrúpeda, y es también el clasificador empleado para enumerar animales, mas no seres humanos. ${ }^{2}$ En otras palabras, designa una postura y no una forma corporal. ¿Significa esto que el cuerpo-carne es un cuerpo animal o, por así decir, lo animal del cuerpo? Me parece que no exactamente. Más bien, se trata de un elemento compartido por humanos y animales; un campo primordial que podríamos llamar "substancia" ("cualquier cosa sin forma determinada de la que está formada otra cosa material" [Moliner, 1967]), y esa substancia es fundamentalmente la carne y la sangre. ${ }^{3}$

Un dato revelador para comprender esta clase de cuerpo es que el feto, mientras permanece en el vientre materno, carece de un cuerpo-carne. (Pero sí tiene, en cambio, el segundo tipo de cuerpo, el cuerpo-presencia.) Esto es porque, antes de nacer, la criatura forma parte todavía del cuerpo-carne de su madre. Mientras el feto permanezca en el vientre vive gracias a la sangre materna: respira y se alimenta de ella. El flujo menstrual es interpretado como la sangre destinada al feto, y que por no existir éste simplemente es expulsada y desperdiciada. El feto, por tanto, carece de un sistema sanguíneo independiente, el cual es, como hemos visto, el principal criterio que define al cuerpo-carne; de hecho, se afirma que el corazón de la criatura no comienza a palpitar hasta que se produce el nacimiento. Sólo a partir de ese momento el recién nacido adquiere un cuerpocarne propio. Pero incluso entonces el nuevo cuerpo-carne no es totalmente independiente y el bebé necesitará seguir "respirando" a través de la madre. Es por esta razón que el corte del cordón umbilical se retrasa todo lo posible, y por lo que también el bebé deberá seguir siendo amamantado, pues la leche materna no sólo transmite alimento sino también aire. Incluso durante el largo periodo en que la madre cargue en la espalda a la criatura, en una especie de respiración

\footnotetext{
${ }^{2}$ La raíz verbal kojt indica la posición que adoptan los animales "a cuatro patas" y los bípedos con plumas (Levinson, 1994: 838), y también el banquito tradicional indígena, el cual suele estar labrado con la forma de un animal, generalmente un armadillo.

${ }^{3}$ Como me hizo notar un amigo tzeltal, en el mito de la aparición del Sol los animales se originan en la carne de los humanos: el niño Xut, que luego se convertirá en el Sol, mata a sus hermanos mayores, y de cada uno de los fragmentos corporales de éstos se origina una especie animal. Es esto, en definitiva, lo que determina el destino alimentario del cuerpo-carne: comer o ser comido, y la discusión se resume en saber qué animal precede a otro en la cadena predatoria. Es, sin embargo significativo que el mito no mencione predadores poderosos — como los grandes felinos- surgiendo del cuerpo humano de los hermanos mayores, pues aquí siempre cabe la duda de quién es la presa, si éstos o los humanos.
} 
transferida, el estado de su sangre — caliente, fría, etc.- continuará gestando al bebé (Moreno, 2011).

Así pues, para que pueda comenzar a producirse un cuerpo-carne se requieren unas condiciones espacio-temporales ordinarias —estar en "este mundo" y en "este tiempo"-, de las cuales son garantes la luz y el calor del Sol (Gossen, 1974). Pero mientras permanece sumido en el frío y oscuridad del seno materno, el no nato se encuentra todavía en un estado "sagrado". Desprovisto de un cuerpo-carne y alimentándose exclusivamente de sangre, su naturaleza se encuentra más próxima a los espíritus que a los seres humanos. Y si bien los pueblos mayas no parecen llegar a compartir la idea extrema de los quechuas de Bolivia según la cual el feto no es sino un pequeño demonio devorador procedente de los tiempos presolares que, por alimentarse de sangre, va consumiendo a su madre durante la gestación (Platt, 2001), no cabe duda de que el feto precisa nutrirse de la sangre materna (Nájera, 2000). Si esto es así es porque carece de este fluido, el cual define al cuerpo carnal. No parece forzado suponer que la extraordinaria atracción que exhiben los seres sagrados mesoamericanos tanto por la carne como, muy especialmente, por la sangre de los seres humanos - abiertamente en tiempos precolombinos mediante los sacrificios humanos, de manera camuflada en la actualidad a través del sacrificio de animales u otras analogías eufemísticas - responde al impulso por obtener aquello de lo cual precisamente carecen. ${ }^{4}$

\section{El “cuerpo-presencia”}

El segundo cuerpo, winkilel, comprende el conjunto del cuerpo humano, incluido el cabello, las uñas y los huesos. Mis informantes indígenas destacan que este cuerpo está formado por "todo", incluido el interior del cuerpo. Pero de sus descripciones se deduce claramente que este cuerpo se caracteriza por ser algo visible. No tanto lo visible del cuerpo, cuanto un cuerpo que existe para ser visto, percibido, y también a través del cual tiene lugar la percepción; esto es, un cuer-

\footnotetext{
${ }^{4}$ Pensando en el sentido del sacrificio humano precolombino, cabe conjeturar que lo que se brindara a las divinidades fuera justamente un cuerpo-carne y no un cuerpo-presencia. Entre los aztecas, a las víctimas se les cortaba el cabello de la corona de la cabeza, y a los niños sacrificados al dios de la lluvia se les arrancaba las uñas, esto es, como si se tratara de ofrecer materia carnal y sangre exclusivamente. De modo que si el canibalismo ritual está dirigido a asimilar el sujeto que hay en la víctima, y la caza requiere la des-subjetivación de la presa, entonces el sacrificio humano mesoamericano estaría más cerca de la segunda que del primero. Si tenemos presente además que algunas partes del cuerpo ofrendado eran también consumidas por los sacrificadores, cabe pensar que el sacrificado era convertido en una presa "animal" (no específica) destinada a ser compartida en comunión por humanos y divinidades. En este sentido, Michael Graulich (1997) ha observado la estrecha relación que existía en el México antiguo entre el sacrificio humano y la cacería: la guerra era simbólicamente asociada a una expedición de caza cuyo objetivo era la obtención de presas humanas identificadas con animales.
} 
po involucrado en relaciones intersubjetivas con otros cuerpos semejantes. Es en este sentido que traduzco winkilel como "cuerpo-presencia". El cuerpo-presencia es la figura, la forma corporal, el semblante, la forma de hablar, la manera de caminar, de vestir la ropa. Si veo a alguien en la distancia puedo decir que parece el winkilel de Pedro, aunque luego resulte ser otra persona. Es lo que se recuerda de una persona fallecida y lo que se presiente de una criatura antes de nacer. ${ }^{5}$

Podemos tratar de precisar un poco más esta idea de "presencia" prestando atención a la raíz del término — win-, cuyo significado es "aparecer", "mostrarse". 6 Se trata de un morfema que da lugar a un campo semántico muy extenso en las lenguas mayas. Se encuentra en la palabra winik, la cual se traduce comúnmente por ser humano, cuerpo o persona. ${ }^{7}$ Posee también el significado de "corpulencia", lo cual es aquí un dato esencial, pues, a diferencia del cuerpocarne, que se define por la substancia que lo compone, el cuerpo-presencia se caracteriza por ocupar un volumen en el sentido de res extensa: la extensión en longitud, anchura y profundidad. Por otra parte, un examen de los diccionarios de lenguas mayas, contemporáneos y coloniales, demuestra que la distinción léxica entre lo que vengo llamando un cuerpo-presencia y un cuerpo-carne es algo común a esta familia linguística. Junto con winik o sus cognadas para traducir cuerpo y/o persona, aparecen otros términos, en este caso muy distintos entre sí, que designan un cuerpo carnal, como se deduce del hecho de que su raíz significa "carne" en la lengua en cuestión, y de que al menos en las lenguas de Chiapas tampoco incluyen los huesos ni el cabello. ${ }^{8}$

Sospecho que el término win fue tomado de las lenguas mixe-zoques, donde está asociado con cosas tales como el poder (capacidad de hacer algo) el rostro, la superficie, el cuerpo, uno mismo (forma reflexiva del pronombre personal), envoltura y, también, máscara. Es decir, algo destinado a ser mostrado, pero que

${ }^{5}$ ¿Incluye este cuerpo también la ropa y los adornos? En este punto mis informantes parecen vacilar. Por una parte, el cuerpo-presencia es considerado como algo permanente, y la ropa, como me hacían ver, es algo que se quita y se pone, se cambia; este cuerpo puede quedar desnudo - a diferencia del cuerpo-carne, que parece ser pensado como ni vestido ni desnudoparte, resulta igualmente evidente que el cuerpo-presencia tiende a ser pensado vestido, como si la vestimenta como atributo resultara indispensable en este cuerpo. Mario H. Ruz (1996: 105) hace notar cómo en el vocabulario tzeltal de Domingo de Ara del siglo xvı, si bien apenas hay referencias al cuerpo en sí mismo, aparecen en cambio numerosas menciones a la ropa como cuerpo, como si hablar de la ropa fuera, en definitiva, hablar del cuerpo-presencia. Como veremos más adelante, algunos espíritus adoptan un cuerpo-presencia vistiéndose y adornándose.

${ }^{6}$ El diccionario de lengua tzotzil de Robert Laughlin (1975) traduce este verbo por "aparecer, ser expuesto, ser visto, ser escuchado, ser distinguido, darse a conocer".

${ }^{7}$ En el diccionario etimológico de las lenguas mayas compilado por Terence Kaufman (2003), winik (y sus cognadas) abarca los significados de persona, cuerpo, ser humano, gente, natural (indígena), llegar a ser hombre, dueño, corpulencia, y en algunas lenguas como el quiché y el tzutujil se encuentra en la raíz de producir, crear, inventar.

${ }^{8}$ Entre los nahuas de la sierra de Puebla se reconoce un cuerpo carnal (nacayo: la carne, los músculos) y otro denominado nequetzaliz, cuya raíz posee el significado de "erguir", "enderezar", y que según Alessandro Lupo (2009: 525) designa el cuerpo en posición vertical y con figura humana. 
también sirve para ver. Por lo demás, esta identificación indígena del yo ("uno mismo") con la máscara, es decir, con algo externo a la carne, nos recuerda que también en la tradición occidental — como sabemos desde el celebre ensayo de Marcel Mauss (1971) - la máscara se encuentra en el origen del sentido primitivo de la noción de persona, lo que no deja de ser una intrigante coincidencia. Encontramos también la raíz del término para cuerpo-presencia en winal, cada una de las unidades de veinte días del calendario solar maya, y en el número veinte, hasta el punto de que Dennis Tedlock (1993) define el término quiché winak ("ser humano") como "ser vigesimal”, una traducción quizá un poco forzada, pero que expresa bien el carácter constitutivo de los veinte dígitos. ${ }^{9}$ Todo lo cual tiene abundantes implicaciones que no podemos desarrollar aquí, pero que, en todo caso, demuestra que la observación de Roy Wagner (2010: XV) de que los mayas nunca inventaron el principio de la rueda, "pero sólo porque éste les inventó a ellos" ("but only because it had invented them"), debe tomarse de manera totalmente literal. ${ }^{10}$

¿Qué clase de seres tienen un cuerpo-presencia (winkilel)? Con seguridad, no los vegetales, tal y como sucede con el cuerpo-carne, pero sí en cambio los animales, porque éstos “caminan, juegan, trabajan, viven en casas, tienen descendencia”. Ahora bien, los animales tienen un cuerpo-presencia sólo en la medida en que se relacionen con los miembros de su misma especie. Un conejo sólo tiene un cuerpo-presencia si es visto por otro conejo o, más precisamente, es tener un cuerpo-presencia de conejo lo que permite relacionarse con otros conejos. En cambio, para los humanos, como para las demás especies animales,

\footnotetext{
${ }^{9}$ Los tzeltales relacionan explícitamente el cuerpo-presencia con los cinco meses (winkil) de la temporada de lluvias, entre mayo y agosto, la época de "aparición" (win), del crecimiento del maíz y también de la aparición de animalillos, los cuales sin embargo no alcanzan un tamaño suficiente para ser comidos hasta el comienzo del siguiente periodo — pom-, el mes de los muertos: un periodo de escasez, por tanto. La temporada de lluvias es la etapa anual asociada a la noche, y que, como ha observado Johannes Neurath entre los huicholes, es un tiempo "preexistente, individualista, espontáneo, creativo" (2008: 30-31). Probablemente por ello en las lenguas mayas este cuerpo se asocia — como recoge el diccionario de Kaufman ya citado — con la capacidad de invención e innovación. Quizá sea significativo que en los dialectos tzotziles de Zinacantán (Laughlin, 1975) y Chamula (Gossen, comunicación personal) el cuerpo-carne, es decir, el cuerpo no asociado a la temporada de lluvias, se llama tacupalil, cuyo significado es "seco" o "sequedad". Transpuesto al plano filogenético, winal significa "generación" en sus dos acepciones, y los tzeltales lo identifican también con el tiempo presolar cuando sobre la tierra aparecían generaciones de humanos que sólo vivían veinte años y al final de este ciclo debían ser sustituidas porque eran incapaces de reproducirse.

${ }^{10}$ Mis informantes asocian espontáneamente el cuerpo-presencia y la temporada de lluvias con el conocido relato del jaguar y el tlacoache (donde éste último engaña sucesivamente y finalmente mata y devora al felino). Se trata de una asociación estructuralmente previsible, pues como ha mostrado Levi-Strauss (1972) para la mitología sudamericana en general, y Hugh-Jones (1979) para los desana de Colombia, el tlacoache está asociado al cambio de estación, de lluviosa a seca en el hemisferio sur, de seca a lluviosa en el norte. En tzeltal, los dos meses que preceden a los de la temporada de lluvia se llaman muk' uch' y tut uch' ("gran tlacoache" y "pequeño tlacoache"). Por lo demás, el tlacoache es un personaje embaucador — un trickster-, asociado, como el periodo de lluvias mismo, con la invención y la novedad de productos y formas.
} 
los conejos tienen esencialmente un cuerpo-carne, como sucede a la inversa para los conejos. El cuerpo-presencia, pues, sólo es perceptible, sólo hace un completo "acto de presencia", entre seres que pertenezcan a una misma especie. En consecuencia, si el cuerpo-carne funciona como una suerte de materia transespecífica, el cuerpo-presencia sólo se actualiza intraespecíficamente. En lengua tzeltal, el clasificador numeral para el "cuerpo-presencia" entre los humanos es tul, que denota una posición bípeda y una figura característicamente humana, mientras que el clasificador numeral para el cuerpo-carne es kojt, el cual, como veíamos, indica una postura cuadrúpeda. En fin, mientras el cuerpo-carne no posee una forma determinada, el cuerpo-presencia tiene, en cambio, una forma específicamente humana. ${ }^{11}$

Como tan lucidamente han destacado Anne-Christine Taylor y Eduardo Viveiros de Castro (2006) a propósito de la región amazónica, desde un punto de vista indígena toda especie constituye una sociedad, y cada sociedad representa una especie. Lo mismo vale en tzeltal: una especie es definida y su extensión limitada por la capacidad de relacionarse por medio del cuerpo-presencia, esto es, de establecer una sociabilidad mediante este cuerpo. Toda diferencia sociológica es también una diferencia ontológica, y viceversa. Probablemente, el término conceptualmente más cercano en lengua tzeltal al europeo indio o indígena es swinkilel lum, literalmente "cuerpo-presencia del lugar". No obstante, puede traducirse también como "dueño del lugar": si se pregunta a un tzeltal qué significa winkilel ("cuerpo-presencia") lo mas probable es que responda que "dueño". Lo que indica esta expresión es que cada clase de cuerpo-presencia se encuentra asociada a un tipo de lugar específico: los indígenas viven en sus aldeas, los europeos en las ciudades o los ranchos, los jaguares en la selva. En este sentido, cada tipo de cuerpo-presencia es "dueño" o domina, en el sentido de que ocupa un dominio, cierto territorio. ${ }^{12}$ No se trata, sin embargo, tanto de un espacio físico cuanto ontológico: cada clase de cuerpo-presencia, cada especie, posee una suerte de ecosistema cultural que no interfiere geográficamente con el de otras especies, y que es aquel que le resulta apropiado.

No obstante, la separación entre especies-sociedades es más una cuestión de grado que un hecho absoluto, y a menudo se producen tanto solapamientos como divisiones entre especies, como demuestra el caso de los humanos. En principio, desde un punto de vista indígena, los europeos son suficientemente sub especie humana, pero este reconocimiento no es automático, sencillo ni completo. El hecho de que no hablemos la misma lengua y no compartamos los mismos hábitos revela un cuerpo-presencia en parte distinto, lo cual impide un intercambio social fluido. Entre europeos e indígenas ciertos aspectos corporales

\footnotetext{
${ }^{11}$ Tanto Anne Christine Taylor (1996: 205) como Alexandre Surrallés (2003) señalan cómo entre los grupos jíbaros es la apariencia aquello que diferencia las especies entre sí.

${ }^{12}$ Lo cual es también cierto para otras lenguas mayas, según se desprende del diccionario de Kaufman (2003), así como para la lengua náhuatl —clásica y contemporánea— cuyo vocablo tlacatl, se traduce como "persona" (humana y no humana) y como "dueño" o "señor" (Chamoux, 1996).
} 
se vuelven, casi literalmente, invisibles para unos y otros, y en la medida en que la presencia se desvanece parcialmente lo que emerge parcialmente también es el común cuerpo carnal (el cuerpo que es, paradójicamente como veremos, menos "natural”). Aquí la cuestión crucial es, por supuesto, si seres con un cuerpopresencia parcialmente distinto pueden ser desposados y fecundados para tener descendencia ( $c f$. Crocker, 1992), dado que es la imposibilidad de engendrar descendientes lo que marca los límites efectivos de una sociedad-especie. De ahí la endémica sospecha indígena de que la mezcla entre europeos e indígenas - pero también entre pueblos indígenas de distintas lenguas y hábitos- produzca hijos deformes, idiotas o albinos. Lo cual también explica la fuerte asociación del cuerpo-presencia con la sexualidad y la capacidad de generación y reposición de seres humanos, hasta el punto de que en numerosas lenguas mayas winkilel designa también los genitales (a veces sólo los masculinos, a veces también los femeninos) como si estos representaran metonímicamente el cuerpo-presencia.

Por último, si en las culturas amerindias el aspecto de la persona que debe ser fabricado es el cuerpo, puesto que el alma es el principio dado (Viveiros de Castro, 2002a), ¿podemos reconocer entre los dos cuerpos tzeltales un distinto grado de artificialidad? No cabe duda que ambos cuerpos requieren ser fabricados de una manera continua. Por un lado, el cuerpo-carne es resultado directo tanto de la alimentación (la comida se incorpora literalmente como carne y sangre) como de ciertas condiciones ambientales (especialmente la temperatura, que resulta en la diferencia entre la tierra caliente y la tierra fría). Por otra, el cuerpo-presencia es fruto de los hábitos sociales de la especie/cultura (etiqueta social, lenguaje, gestos, indumentaria, etc.). Así pues, ambos procedimientos —alimentación y código social - son necesarios para alcanzar un único desarrollo biomoral (Pitarch, 2008). Pero conforme a la tesis de Wagner (1981) según la cual las "culturas tribales" invierten el contenido de aquello que es considerado lo innato y lo artificial (esto es, la "naturaleza” y la "cultura”), el cuerpo más fabricado, menos "natural”, es el cuerpo-carnal, contrariamente a lo que dicta nuestro sentido común. Hemos visto como este último tipo de cuerpo sólo comienza a producirse después del alumbramiento, mientras que el cuerpo-presencia inicia su formación ya dentro del vientre materno (esa especie de cámara de incorporar). Y en efecto, este último está significativamente asociado con el mundo presolar, la temporada de lluvias y el mundo nocturno —esto es, a las "convenciones innatas"- ${ }^{13}$ Así pues, de los dos cuerpos, el cuerpo-carne es el más dúctil, más susceptible de ser modificado por la actividad humana. En consecuencia, toda alteración del cuerpo-presencia debe estar precedida de una modificación del cuerpo-carnal. Como sabe cualquier padre indígena, para que por ejemplo un niño pueda llegar a ser maestro de escuela (y obtener así un salario del gobierno), el primer y prin-

${ }^{13} \mathrm{Si}$ proyectamos la ontogénesis sobre la filogénesis, parece razonable suponer que los humanos que aparecen en los mitos sean pensados como poseyendo únicamente un cuerpo-presencia, y sólo la emergencia del Sol —equivalente al nacimiento individual - permita la creación de un cuerpo carnal. 
cipal requisito es sustituir la dieta de maíz y frijol por galletas de trigo, carne de res y alimentos comerciales. Es precisamente esta comida la que, literalmente, le permitirá aprender tanto a hablar español como a leer y escribir.

\section{Los dos cuerpos en los cantos chamánicos}

Si examinamos las diferencias entre los dos cuerpos de un modo más ordenado, veremos que éstas pueden organizarse al menos en torno a dos pares de contrastes: divisibilidad / totalidad, y pasividad / actividad. El cuerpo-carne se caracteriza por ser una reunión de partes y tener un carácter pasivo; el cuerpopresencia, por ser un conjunto integrado y activo. Donde más claramente se revela esta distinción es en los cantos chamánicos de curación. Y si bien todos los tzeltales reconocen la distinción entre los dos cuerpos, es en el contexto del chamanismo y las prácticas terapéuticas donde ésta se aplica de modo más sistemático y deliberado. Fue de hecho trabajando en la traducción de los cantos chamánicos donde pude reconocer por primera vez la diferencia entre los dos cuerpos. Los tzeltales organizan estos cantos en dos grandes géneros (poxil y ch'abatayel), cuyo principal criterio de distinción (implícito) es que los primeros están dirigidos al cuerpo-carne y los segundos al cuerpo-presencia. Ambos cuerpos son vulnerables a la enfermedad, pero lo son de una manera distinta: el primero es prácticamente una presa de los espíritus, el segundo es víctima de los sentimientos de estos.

En los cantos dirigidos al cuerpo-carne, la impresión no es tanto la de un cuerpo que está enfermo, cuanto que una de sus partes ha sido atacada. El conflicto se produce, pues, entre una parte del cuerpo y el objeto patógeno intruso, y la curación consiste en la extracción de ese objeto de la parte afectada; de hecho, en estos cantos raramente se cita al cuerpo-carne (bak'etal) en su conjunto. El siguiente fragmento, por ejemplo, pertenece a un canto dirigido a tratar cierto tipo de locura (chawaj). En el cuerpo-carne del paciente se ha introducido la enfermedad - a quien pertenece la voz que escuchamos en el texto- en forma de palabras, y estas se han instalado en ciertos lugares: el corazón, la oreja, el pecho y el hígado (generalmente, las enfermedades se concentran en una o dos partes, aunque las locuras tienden a extenderse algo más); el resto del cuerpo, sin embargo, no se encuentra necesariamente enfermo:

nakalon yo'tik

pejtsajon xiatwan

ta yolil sni' yo'tan xiatwan

ta yolil sejkub yo'tik xiatwan

ta yolil sti' xmoch yo'tik

najkajon ta xujk xchikin xiatwan yo'tik

jich ajulon ta chij

julon ta bak'et me he instalado

me he asido

en el centro de la punta de su corazón

en el centro de su hígado

en el centro de su pecho

me he instalado en el borde de su oreja

así he llegado a la vena

así he llegado hasta la carne 
jul jk'opon chij

jul jk'opon bak'et

jich anajkajon xiatwan

jich apetsajon xiatwan

jich la kich' kisim yo'tik xiatwan

jich la jkich' jlop' yo'tik xiatwan he llegado a hablar a la vena

he llegado a hablar a la carne

así me he alojado

así me he asido

así he puesto mi raíz

así he extendido mi rizoma

En los cantos de este género se enumeran detalladamente ciertas partes del cuerpo y se describe minuciosamente la manera en que la enfermedad se ensaña con ellas. En contrapartida, en los cantos dirigidos a tratar el cuerpo-presencia no se nombran partes concretas. El cuerpo-presencia presenta una forma singular. El fragmento siguiente, por ejemplo, pertenece a un canto para curar un cuerpopresencia afectado por el resentimiento de un muerto reciente ("los difuntos huesos, los difuntos cabellos”); pero se notará que en este caso la enfermedad afecta la totalidad del cuerpo o, más exactamente, el cuerpo como totalidad:

manchuk me yak'beyiktel ta swinkilel
manchuk yak'beyiktel ta yo'tan
anima baketik yo'tikoni
anima tsotsetik yo'tikoni
mame tey xyak'bonix stukel
balumilal sikil yokike
balumilal sikil sk'abike
balumilal sti'tombail
balumilal skuchtombail
ak'olok me jajchel yo'tan
ak'olok jajchel swinkilel
manchuk ja'uk xanix ay stsa'nelali
ay xanix sk'un k'aaleli
ay xanix sikil swinkileloni
ay xanix sikil sti'ik yo'tikoni
ay xanix sikil sk'opik yo'tikoni
anima baketetik yo'tikoni
anima tsotsetik yo'tikoni

\author{
que no contagien su cuerpo \\ que no contagien su corazón \\ los difuntos huesos \\ los difuntos cabellos \\ que no le contagien con \\ el intenso frío de sus pies \\ el intenso frío de sus manos \\ con su inmenso resentimiento \\ con su inmenso rencor \\ que se levante su corazón \\ que se levante su cuerpo \\ que no sufra ya la diarrea \\ la fiebre ligera \\ el frío en su cuerpo \\ por causa de las heladas palabras \\ de los glaciales discursos \\ de los difuntos huesos \\ de los difuntos cabellos
}

En cuanto al segundo contraste - pasividad /actividad-, puede decirse que el cuerpo-carne funciona como un objeto, mientras el cuerpo-presencia como un sujeto. ${ }^{14} \mathrm{Si}$ en los cantos chamánicos el cuerpo-carne -o las partes que lo forman - es mostrado como una presa inerme y sin voz, víctima muda de la enfermedad y objeto pasivo de las manipulaciones rituales del chamán, el cuerpopresencia, por el contrario, deja sentir su presencia interviniendo activamente en los diálogos: lamentándose, informando, acusando, describiendo.

\footnotetext{
${ }^{14}$ Simplifico aquí, pues dado que el tzeltal es una lengua ergativa la distinción más precisa sería entre un cuerpo transitivo y otro intransitivo. Debo a Lydia Rodríguez haberme llamado la atención sobre este punto, que necesita ser investigado con más detenimiento.
} 
Es esto en definitiva lo que define el cuerpo-presencia: hacer cosas. "Trabaja", "pasea", "juega”, "habla". Cuando en los cantos dirigidos a su curación son citadas partes concretas, éstas no son tanto fragmentos anatómicos cuanto actividades corporales. Tales actividades son enunciadas en forma de paralelos semánticos. El par "corazón / labios" expresa la función del lenguaje, de acuerdo con la teoría indígena de que las palabras brotan del corazón y ascienden hasta la boca, donde son articuladas por los labios para producir un habla adecuada. El par "mirada / rostro" remite a la capacidad de los sentidos (vista, oído y gusto/ olfato), que está en efecto asociada al cuerpo-presencia. Pero sin duda el más importante de estos paralelos es el de "manos / pies" o, su equivalente, "brazos / piernas" (el total de veinte dígitos, que funciona comúnmente como sinécdoque de este cuerpo), que se refiere a la facultad del movimiento articulado, y con ella, a la capacidad de trabajar. La etnografía mesoamericana ha subrayado a menudo cómo el trabajo representa un rasgo definitorio de la humanidad.

En este punto podemos aportar un dato etnográfico suplementario, pero revelador. En tzeltal, el cuerpo-presencia lava el cuerpo-carne: atintesa te abak'etal, "lava tu cuerpo-carne", se le ordena por ejemplo a un niño (o bien, atinan te $a k^{\prime}$ ojtol). Pero, conforme a su naturaleza no agentiva, el cuerpo-carne no puede lavar el cuerpo-presencia. No es, sin embargo, el cuerpo-presencia aquello que debe ser lavado: todos los indígenas a quienes pregunté veían absurda la idea de lavar su cuerpo-presencia, esto es, de lavarse a sí mismos. En otras palabras, si el cuerpo-carne es visto como un objeto y el cuerpo-presencia experimentado como un sujeto, estas posiciones no son reversibles. En un conocido pasaje, Merleau-Ponty afirma que lo que define al cuerpo (esto es, la idea europea del cuerpo) es su reversibilidad. Nuestra mano derecha nunca toca la izquierda cuando la mano izquierda toca la derecha; cuando una hace de sujeto, la otra hace de objeto. Ahora bien, "cuando una de mis manos toca la otra, el mundo de cada una de ellas se abre al de la otra porque la operación es facultativamente reversible" (Merleau-Ponty, 1970: 175-176). Es esta posibilidad permanente de reversión lo que confirma que se trata de un mismo cuerpo. Pero entre los dos cuerpos indígenas - el cuerpo subjetivo y el cuerpo carnal — no hay posibilidad de reversión; si mi mano, como parte de la totalidad del cuerpo-presencia, puede tocar mi carne, mi carne (mis músculos, mi piel, mis venas, etc.) no pueden tocar mi mano.

\section{Inciso: un cuerpo inorgánico}

Cabe pensar que una de las consecuencias que comporta la distinción entre un cuerpo pasivo y divisible y otro activo e integrado es la de prevenir la idea de un cuerpo orgánico. Un órgano es una parte discreta del cuerpo que desempeña una función. Ahora bien, en la medida en que los órganos son partes, debieran pertenecer al cuerpo-carne (divisible, inactivo), pero puesto que desempeñan funciones, debieran corresponder al cuerpo-presencia (una totalidad activa). No 
hay lugar, pues, para la idea de órgano: sólo puede haber o bien partes inactivas o bien una unidad agentiva, pero no una combinación de ambas. Nos encontramos, así, con una idea de cuerpo humano que dista mucho de la europea del cuerpo como organismo.

Partes internas, pero sin funciones. Ello explicaría el escaso interés indígena por la composición y funcionamiento internos del cuerpo. Esto es algo que la etnografía de esta región ha notado con frecuencia: la anatomía indígena presta muy poca atención a la composición interna del cuerpo, y no parece existir nada semejante a una "anatomía fisiológica", lo cual ha sido justificado como consecuencia de la ausencia de prácticas quirúrgicas (Eloise y Brent Berlin, 1996: 55). Y, sin embargo, los indígenas que han emigrado por varias generaciones a las ciudades, donde están expuestos incesantemente a imágenes del interior del cuerpo (en la escuela, en las láminas de las farmacias y de los hospitales, etc.), parecen seguir mostrando tan poco interés por éste como los indígenas más tradicionales. ${ }^{15}$ Quizá es por ello que la práctica chamánica —que, como he mencionado, es donde se lleva la distinción entre los dos cuerpos a su máxima expresión- manifiesta la mayor indiferencia por el interior del cuerpo humano y sus posibles funciones, hasta el punto de que, en teoría, los chamanes nunca deben manipular el cuerpo de sus pacientes.

En el fondo, la distinción de los dos cuerpos rehuye la oposición interioridad/exterioridad, lo cual, a su vez, implica el rechazo de la noción de interioridad subjetiva. Sabemos que esta oposición regula la casi totalidad de la visión europea de la corporalidad, la cual engendra la idea de un interior que por definición contiene, a la vez que oculta, lo principal de la persona: la conciencia, las emociones, los traumas, etc., es decir, todo aquello que se guarda "dentro" y sólo ocasionalmente sube a la superficie. Pero no debemos perder de vista que esta interioridad sicológica europea tiene un fundamento orgánico, como sucede por ejemplo en la teoría hipocrática de los humores: es esto lo que asegura en definitiva la reunión de los aspectos somáticos y subjetivos. La idea europea del cuerpo como organismo es lo que convierte a aquel en una totalidad indivisible que impide que los dos cuerpos puedan ser pensados por separado.

El interior del cuerpo indígena, por el contrario, está desprovisto de subjetividad. Es verdad que parte de lo que la tradición europea proyecta sobre la interioridad —aspectos del carácter, las emociones, etc.—, los indígenas lo hacen sobre sus almas, las cuales suelen encontrarse instaladas en el corazón o en alguna otra parte interna. Mas en este contexto, el corazón no es tanto una víscera

\footnotetext{
${ }^{15}$ Así, por ejemplo, en el estudio clásico de Alfredo López Austin (1980) sobre el cuerpo humano nahua precolombino, los datos sobre su interioridad son, en relación con otros aspectos (centros anímicos, correspondencias cosmológicas, etc.), considerablemente exiguos (como el autor es el primero en notar). Sospecho que las fuentes europeas simplemente reflejan la ausencia de elaboración orgánica nahua. Unos "órganos" que tampoco parecen tener funciones fisiológicas claras, como si la preocupación manifiesta en los textos por lo que "cada uno de ellos hace" reflejara más bien la lógica organicista de los autores europeos como Sahagún o Molina.
} 
como una especie de coágulo del estado sagrado (lo "innato") que ha quedado retenido en el interior del cuerpo por efecto del nacimiento. En realidad, el interior del corazón - lo que pudiéramos entender como el locus de la subjetividad indígena- pertenece a lo más externo, ese otro estado ontológico que representa la antítesis del mundo solar ordinario. Lo que interesa del cuerpo, en definitiva, no es lo que esconde, sino lo que muestra: su “presencia”. Desde este punto de vista, la plástica corporal prevalece sobre la fisiología. Como observa Roland Barthes a propósito del teatro de marionetas japonés, el Bunraku, "la idea de interioridad [...] es sustituida por la acción necesaria para la producción del espectáculo" (1982: 309).

\section{Las dos almas}

Dejemos por un momento los cuerpos tzeltales y fijémonos en las almas. En este caso nos encontramos aparentemente con el problema opuesto al de los cuerpos. Si, como mencionaba al principio, la etnografía del area mesoamericana ha dado por supuesta la existencia de un único cuerpo, en cambio proporciona un repertorio de almas sumamente extenso y particularista, el cual viene a complicarse aun más por el hecho de que las almas se dividan o multipliquen fácilmente (de modo que una persona pueda contener gran número de estos fragmentos sagrados). Con todo, si prestamos atención exclusivamente al tipo de "cuerpo" que tienen las almas podemos reducir drásticamente esta complejidad hasta distinguir básicamente dos clases: a) un alma que posee la figura del cuerpo humano; y b) un alma asociada a un animal, a un fenómeno atmosférico o a cualquier otro tipo de ser y que responde a una forma no humana. ${ }^{16}$

Mencionaré tres ejemplos, entre los muchos posibles. Los chatinos de Oaxaca distinguen un alma humana (tyi ${ }^{\prime} i$ ), que abandona fácilmente el cuerpo durante la enfermedad y el sueño, de otra llamada ni co ne asociada a un animal o, más raramente, a fenómenos atmosféricos como rayos, vientos o centellas (Bartolomé y Barabas, 1996: 225-234). Los nahuas de la sierra de Puebla poseen un alma llamada ecahuil, esto es "sombra", con la misma forma del cuerpo humano individual, y otra llamada tonal, zoomorfa y cuyo número varia entre uno y trece (Lupo, 2009: 527-528). Los yaquis de Sonora diferencian el seewa taka, el cual posee exactamente el mismo aspecto del cuerpo donde se aloja, del jiapsi que

\footnotetext{
16 También en el estudio de Akë Hultkrantz sobre América del Norte puede reconocerse la presencia general de dos tipos de alma: una con la misma silueta del cuerpo humano que la aloja, un "doble" comúnmente llamado "sombra" o "imagen"; y otra clase de alma que se muestra en distintas formas no humanas, en la gran mayoría de los casos como animales, pero en algunos otros como árboles, flores o incluso ríos, huesos o piedras (1953: 256-258). Igualmente Viveiros de Castro observa sobre la región amazónica: "me parece que la distinción básica a hacer es entre un concepto de alma como representación del cuerpo y otro concepto de alma que no designa una simple imagen del cuerpo, mas lo otro del cuerpo" (2002b: 443).
} 
cuando sale del cuerpo lo hace en forma de ave, una paloma u otro tipo de pájaro (Olavarria, Aguilar y Merino, 2009: 55-72). ${ }^{17}$

Lo que estoy sugiriendo en definitiva es que la distinción entre las dos almas se corresponde con la distinción entre los dos cuerpos: un cuerpo exclusivamente humano definido por la forma, y un cuerpo sustancialmente semejante al de los animales. Las almas mantendrían entre sí, pues, la oposición entre los cuerpos, pero como el reverso inmaterial de estos. Sin embargo, antes de pasar a ver esta homología necesitamos detenernos un poco más en la naturaleza de estas dos clases de almas.

En lengua tzeltal estas se denominan respectivamente ch'ulel y lab, aunque para simplificar las llamaré "alma-humana" y "alma-espíritu". La primera reside en el corazón y es descrita como una sombra con exactamente la misma figura del cuerpo humano que la aloja, incluido el cabello y la ropa: su imagen. Una imagen, aunque paradójicamente invisible a los humanos en condiciones ordinarias mientras divaga exteriorizada del cuerpo durante el sueño o la embriaguez alcohólica. No obstante, fuera de los sueños el alma-humana puede ser vista en ciertos momentos, normalmente durante el crepúsculo, y entonces se distingue una sombra que se desplaza liviana y silenciosa, suspendida como a un metro aproximadamente sobre el suelo. La segunda clase de alma se caracteriza, en cambio, por tener forma no humana: la figura de un animal de cualquier especie, de meteoros como vientos, rayos o arcoíris, o bien de ciertos fantasmas, sobre los cuales volveremos un poco más adelante. Esta alma-espíritu, de la cual una persona puede tener hasta trece versiones alojadas en el corazón, hace que el ser humano comparta el destino del animal u otro ser de los cuales ha adoptado su forma. Para los propósitos de este artículo, la cuestión clave, sin embargo, es que se trata de un alma que a pesar de, o, más precisamente, por ser capaz de asumir cualquiera de las formas corporales propias de los seres del mundo ordinario (con excepción de la humana), carece de una forma corporal dada de antemano. Es probable que en el interior del corazón humano no tenga forma, y sólo cuando sale de él al mundo solar adopta una específica, como sucede en el momento de la muerte cuando estas almas son expelidas por la boca y por un instante se vuelven visibles a los humanos con la forma del animal o meteoro de que se trate.

Desde este punto de vista, el alma-espíritu no hace sino comportarse como el resto de los seres sagrados, a cuyo dominio en definitiva pertenece. Mientras permanecen sumidos en el estado sagrado, los espíritus carecen de forma determinada, esto es, de una identidad estable. Es un estado de "ausencia", una existencia virtual que sólo se actualiza cuando pasan de "este lado" del mundo. Pero a diferencia de los seres humanos, cuyo cuerpo-presencia se halla fijado por

17 Encontramos a veces una tercer alma, una suerte de esencia vital que no debe separarse del cuerpo - por ejemplo, el yolo de los nahuas de la sierra (Lupo, 2009), el “ave del corazón” de los tzeltales (Pitarch, 1996)—, descrita a veces con forma humana, otras con forma animal. 
el cuerpo-carne - lo cual nos somete a una identidad relativamente constante-, los seres sagrados pueden adoptar cuerpos-presencia distintos o simplemente recombinar las piezas que los componen. No me parece que se trate tanto de una metamorfosis en sentido estricto, puesto que no hay una alteración en la forma, como de la adopción y abandono de unos modelos corporales preexistentes. $^{18}$

El hecho de que el alma-espíritu adopte preferentemente formas corporales animales implica que su capacidad de afectar a los humanos sea muy limitada por la razón ya señalada: los cuerpos-presencia de distintas especies apenas pueden relacionarse entre sí. No obstante, existe una clase de estas almas, conocida significativamente como "dadores de enfermedad", capaz de entablar una comunicación inmediata con los humanos con el propósito de infligir enfermedades y en última instancia la muerte. El requisito para ello es que deben fabricarse expresamente un cuerpo humano provisional. Pero se trata de un cuerpo no propiamente indígena, pues hasta donde conozco estas almas nunca adoptan estos últimos, sino el de seres humanos extraños tales como figuras europeas de sacerdotes católicos, funcionarios gubernamentales, maestros de escuela o ganaderos. Este cuerpo-presencia transitorio difiere, sin embargo, del de los humanos por el hecho de que sólo está formado por ropa, accesorios y ornamentos: bajo la indumentaria no hay un cuerpo carnal. Por ejemplo, el cuerpo adoptado por ciertas almas que representa a sacerdotes católicos —un espíritu muy agresivoestá en realidad formado por la vestimenta característica de los curas: un hábito negro o blanco o de vivos colores si se trata de un obispo, zapatos negros de charol, un crucifijo colgando del cuello, el cabello cortado en tonsura, etc; pero para que esta vestimenta pueda sostenerse en pie, el espíritu debe rellenarla con el papel de biblias u otros libros religiosos. En suma, este tipo de cuerpopresencia fabricado funciona como un instrumento provisional que habilita la relación con lo seres humanos; pero una vez utilizado, el cuerpo es desmontado y las ropas son guardadas en algún lugar del bosque o simplemente desechadas. El alma-espíritu que lo ha fabricado deja de poseer un tipo de cuerpo-presencia y con él la facultad de afectar a los humanos. ${ }^{19}$

\footnotetext{
${ }^{18}$ El alma-humana recibe el mismo clasificador numeral ( $\left.t u l\right)$ que el cuerpo-presencia, una forma bípeda con figura humana; en cambio, el clasificador numeral del alma-espíritu es kun, que Berlin (1978: 201) define como "large piles of individuated objects with maximal horizontal extension", esto es, cosas que se enumeran no en relación a su forma, sino por contiguiidad, mediante intervalos. También Hultkrantz observa en América del Norte cómo la segunda alma cambia entre formas: "We have already stressed the fact that the many extra-physical forms in which the free-soul is manifested do not occur simultaneously but alternatingly, so that they exclude one another" (1953: 248).

${ }^{19}$ En ciertos casos excepcionales, la comunicación con los humanos es habilitada no mediante una vestidura completa, sino por el uso de un lenguaje semejante al humano. Esto es lo que hacen, por ejemplo, ciertas aves como los búhos y lechuzas u otros animales considerados "dadores de enfermedad": articulan un lenguaje suficientemente humano como para activar un cuerpo equivalente en parte al de la especie humana (Pitarch, 1996).
} 
Es interesante que varios amigos tzeltales asociaran espontáneamente esta maniobra de fabricación de un cuerpo-presencia por parte de un alma-espíritu con la manufactura del muñeco xutax, es decir, la imagen de Judas tal y como se representa durante la Semana Santa. Los indígenas de Chiapas confeccionan este personaje con una chaqueta y pantalones de fieltro rojo, sombrero, botas, un morral de redecilla, y una máscara de madera ya ennegrecida por el humo del los cigarrillos que se encajan en su boca y que una vez encendidos se consumen lentamente (un alimento muy apropiado para un espíritu). El muñeco se cuelga entonces en la cruz del atrio de la iglesia (figura 1). La ropa está rellena de hojas secas de árbol del plátano (la antítesis de la carne), las cuales se queman o hacen estallar con pólvora al acabar la celebración (figura 2). Ahora bien, la efigie de este muñeco se llama en tzeltal precisamente winkilel, es decir, cuerpo-presencia, y a él solían remitirse mis informantes cuando preguntaba acerca de este cuerpo. ${ }^{20}$

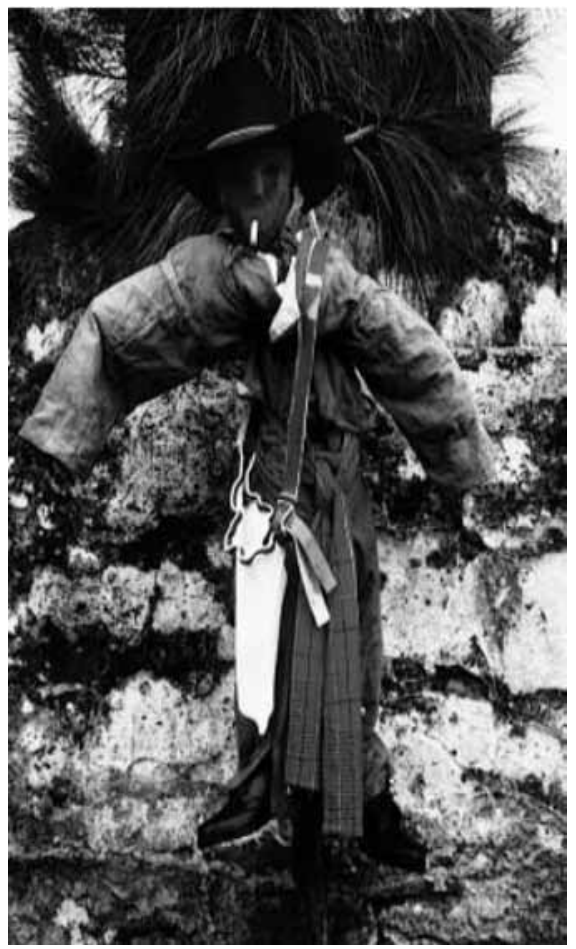

Figura 1. Foto del autor

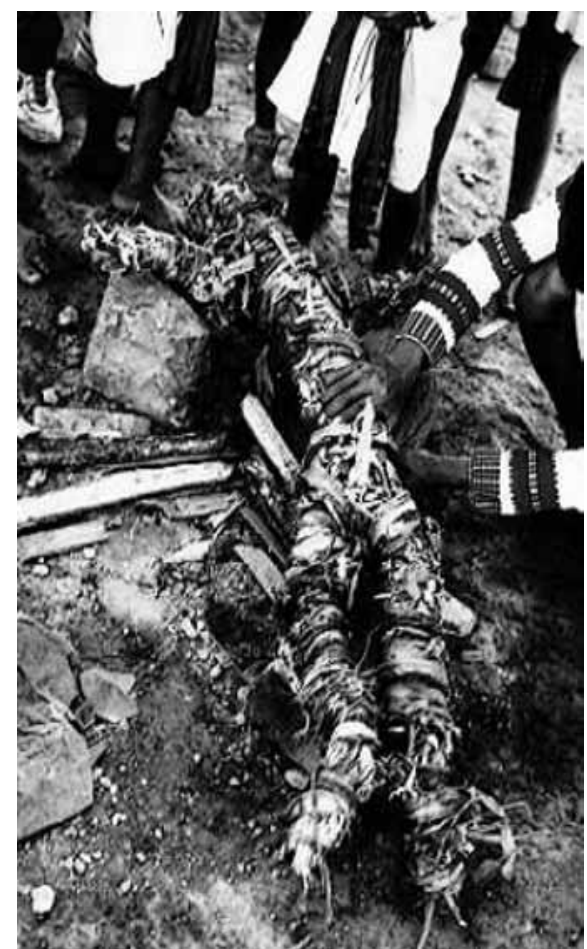

Figura 2 . Foto del autor

${ }^{20}$ Otro dato en el fondo similar: en lengua maya-yucateca el espantapájaros recibe el nombre de winak', que el diccionario Cordemex (Barrera Vázquez, 1980) recoge como "dominguete, espantajo de pájaros, algunas veces se toma y significa fantasma o visión nocturna, espantajo para aves y animalillos como dominguillo". 
Desde luego, este personaje armable y desmontable se encuentra muy extendido entre las poblaciones de la región maya, evidentemente relacionado con el ritual católico. Pero los indígenas parecen haberle dado sus propios significados. Todos ellos están estrechamente asociados con la sexualidad y la reproducción - como sugiere ese fálico cigarro puro encendido en la boca-. El más y mejor conocido de ellos es Max Simón, a orillas del lago Atitlán, cuyo culto se ha extendido a lo largo de Guatemala y cuyo cuerpo de hecho ya ha dejado de desmontarse. ${ }^{21}$ En su etnografía, Michael Mendelson (1963) subraya la relación explícita de Max Simón con la fertilidad humana, pues consiente las violaciones sexuales y las fugas de parejas y él mismo vive con una puta, Magdalena o María Castellana. En contrapartida, Max Simón castiga enérgicamente el bestialismo, quizá porque siendo un cuerpo-presencia su acción sólo puede estar orientada a la reproducción entre humanos. Como quiera que sea, estos casos de incorporación no consisten tanto en animar un objeto inanimado, de "traer a la vida" un objeto, como de suministrar un cuerpo-presencia a un espíritu que en su dominio carece de él. No transformar una identidad, sino producirla o, más precisamente, fijarla momentáneamente. Y al hacerlo, permitir una relación con lo sagrado en un contexto ritual que se encuentra suficientemente bajo control humano. Cuando Ruth Bunzel (1981) preguntó en el pueblo de Chichicastenango por qué se desmontaba al concluir la Semana Santa la figura de Judas, le respondieron: "para que no vaya por ahí asustando gente".

\section{Un modelo cuaternario de la persona}

Tras este inciso sobre las almas volvemos a la correspondencia entre éstas y los cuerpos. Nos encontramos, pues, con que las almas recapitulan, en el plano incorpóreo, el sentido de la oposición original entre los cuerpos: por una parte, un alma intraespecífica (con forma humana entre los humanos) y, por otra, una alma transespecífica (con formas animales que se toman y abandonan consecutivamente). ¿Cuáles son las implicaciones de este esquema paralelo entre cuerpos y almas para entender, como planteaba al principio, las relaciones de continuidad y discontinuidad entre estos elementos y el resto de los seres?

Si nos fijamos primero en la relación entre el cuerpo-presencia y el alma-humana, veremos que ambos principios tienen en común poseer una figura específicamente humana, y más, una figura no genérica sino individual. Ambos elementos representan — cada uno en su respectiva dimensión — un principio diferenciador: distinguen tanto a la especie humana de otras especies animales (y a estas entre sí), como a los humanos individualmente. ${ }^{22}$ Ahora bien, si el cuerpo-presencia se

\footnotetext{
${ }^{21}$ Pudiéramos quizá incluir en esta serie a figuras como Tío, el guardián de la riqueza de las minas bolivianas, que es también representado con un cigarro puro en la boca (Fernández Juárez, 2000; Nash, 1979).

${ }^{22}$ Más aún, entre los tzeltales el alma-humana separa a los parientes afines de los consanguíneos, reuniendo a estos últimos en las montañas ch'iibal, cuyo interior está habitado por los miembros de un mismo patrilinaje.
} 
caracteriza por ocupar un volumen - por su "corpulencia"-, el alma-humana, en cambio, es una sombra sin cuerpo, algo plano sin extensión. Por su parte, el cuerpo-carne y el alma-espíritu tienen en común carecer de una forma concreta. (Hemos visto cómo esta alma, en la medida en que puede adoptar virtualmente cualquier forma, animal u otra, se define por su multicorporalidad potencial, o lo que es lo mismo, por carecer de una forma específica dada de antemano.) Ambos representan, pues, un continuo indiferenciado: el principio de homogeneidad y continuidad entre las especies y los individuos. Pero si el cuerpo-carne se define por la substancia de la que está formado — carne y sangre-, el alma-espíritu se caracteriza por el hecho de ser insubstancial, por carecer de materia carnal.

En la persona indígena podemos distinguir, pues, cuatro aspectos: una forma substancial (cuerpo-presencia), una substancia sin forma (cuerpo-carne), una forma insubstancial (alma-humana) y una insubstancialidad sin forma (alma-espíritu). Ello implica que, en lugar de una oposición exclusivamente binaria cuerpo/alma, nos encontramos con un campo cuaternario que a la vez que refleja la oposición original, también la despliega. Podemos representar visualmente esta configuración relacional mediante el "cuadrado semiótico" desarrollado por Greimas (Greimas y Courtés, 1991: 96-99), el cual nos permite hacer una suerte de transcripción de los datos etnográficos relativos a los cuerpos y almas tzeltales sin restringirnos a un binarismo lógico de la clase uno/otro.

En el cuadro semiótico el significado se produce mediante la elaboración de posibilidades lógicas contenidas en una relación de oposición y sus estructuras de negación y afirmación. Así, por ejemplo, la oposición "blanco" y "negro" produce el siguiente campo de significación:

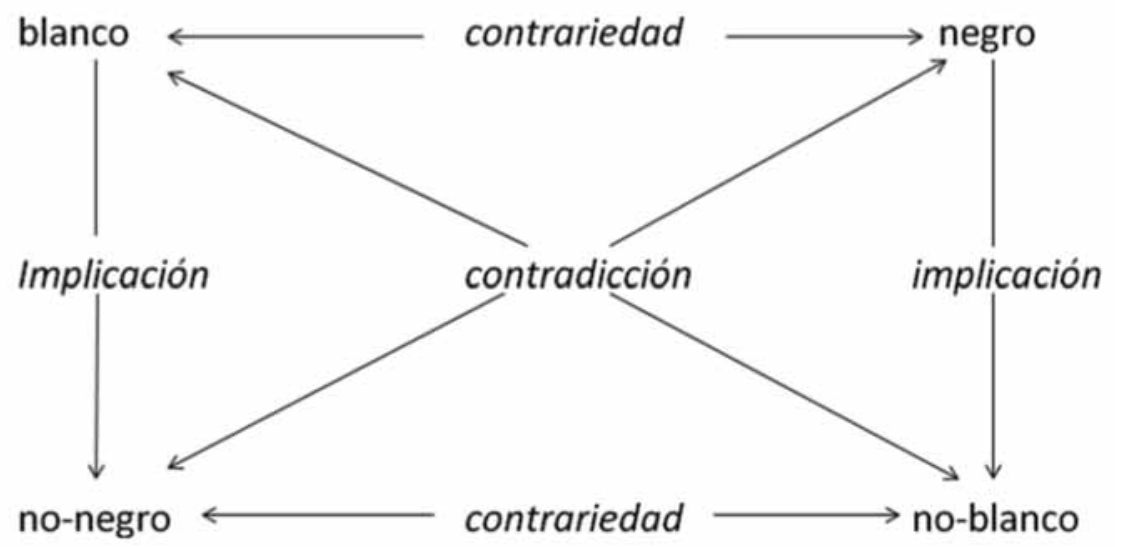

Donde "blanco" y "negro" son contrarios, pero no se contradicen uno al otro, del mismo modo que "no negro" y "no blanco" se oponen sin contradecirse. En cambio, "blanco" y "no blanco" se encuentran en una relación de contradicción: 
la negación de uno es la afirmación del otro y viceversa, así como "negro" y "no negro" son contradictorios en el sentido anterior. Finalmente, "blanco" complementa o implica "no-negro", pero no a la inversa: "no-negro" no implica "blanco"; y, del mismo modo, "negro" implica "no blanco", pero no al revés.

En los términos de la persona indígena, la oposición original entre las dos clases de cuerpo genera - por contradicción y complementariedad- los dos tipos de almas:

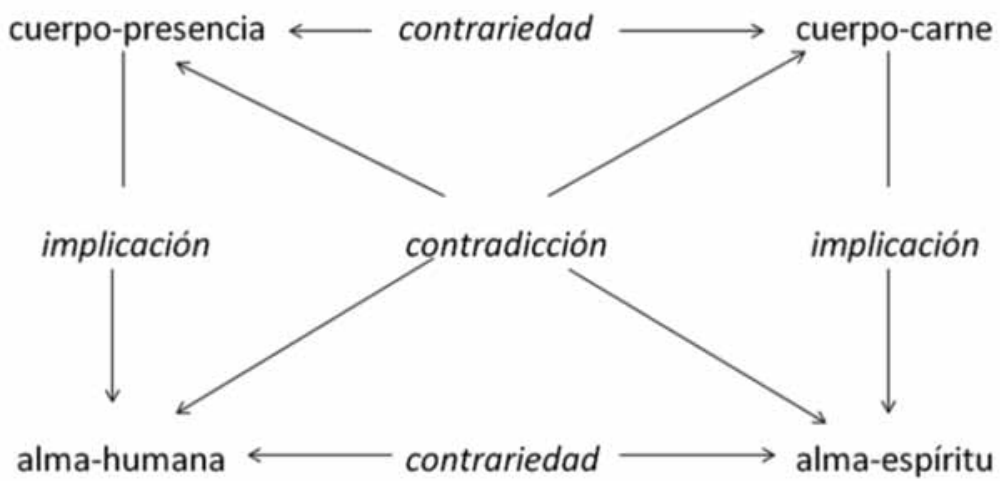

Aquí el cuerpo-presencia se opone al cuerpo-carne en el sentido de que el primero se define por la forma, mientras el segundo por la substancia que lo compone. Pero en esta relación de contrariedad un cuerpo no excluye al otro. No se trata de categorías contradictorias sino concomitantes: la relación de contrariedad, subrayan Greimas y Courtés (1991: 94), es una de "presuposición recíproca”, pues cada uno toma al otro como la base de su existencia semántica. Y, en efecto, ambos cuerpos se requieren para formar un ser humano corporalmente ordinario. Sin el cuerpo-presencia, el cuerpo-carne se queda, como no dejan de resaltar mis informantes, en simple "carne para comer". Sin el cuerpo-carne, el cuerpo-presencia se vuelve, o bien un fantasma compuesto solo de ropa sin un cuerpo debajo de ella, o bien un descarnado esqueleto de largo cabello y uñas, es decir, en un muerto, tal y como estos suelen representarse en la narrativa o en los cantos chamánicos. ${ }^{23}$ Por lo que concierne al eje inferior del cuadro, alma-humana y alma-espíritu también se oponen y presuponen: la primera posee

${ }^{23}$ La representación convencional de los muertos como un esqueleto con cabello no es sino el resultado de sustraer el cuerpo-carne del cuerpo-presencia. Si ciertos seres sagrados se presentan a los humanos, por así decir, con un máximo de cuerpo-presencia mediante la ropa y los ornamentos, otros - como los muertos- se fabrican uno mínimo empleando únicamente los huesos y el cabello (los cuales ni siquiera es seguro que sean originalmente los suyos). Por lo demás, en la región de los Altos de Chiapas en muy conocido el caso de los yalem bak'et ("carne caída"), seres humanos vivos (no espíritus o almas o muertos) que mediante ciertas palabras mágicas pierden su carne y deambulan como esqueletos inflingiendo la muerte, después de lo cual vuelven a reunirse con su carne que yace informemente amontonada a la orilla de un camino o bajo una cruz. 
una forma humana; la segunda, no. Pero si el eje superior se caracteriza por la "presencia”, éste en cambio corresponde al plano de la "ausencia"; las almas son términos puramente negativos o de privación: los "otro" de los cuerpos.

En cambio, la relación diagonal entre el cuerpo-presencia y el alma-espíritu constituye una de contradicción, pues ambas categorías se excluyen mutuamente. Si hay "presencia" — aquello que introduce la discontinuidad, lo discreto-, no puede haber entonces almas-espíritu, esto es, lo continuo, los cuerpos sin solución de continuidad (con la excepción ya vista de algunos espíritus que adoptan un cuerpo-presencia con ciertos fines maléficos: podría decirse entonces que se incorporan en su negación). E igualmente, el alma-humana (una sombra con figura humana) se encuentra en relación de contradicción con el cuerpo-carnal (materia sin forma); si hay substancia, no hay forma sutil, si hay forma sutil, no hay substancia, esto es, no hay carne ni fluidos corporales.

Por último, entre el cuerpo-presencia y el alma-humana, por una parte, y el cuerpo-carne y el alma-espíritu, por otra, se da una relación de complementación. El cuerpo-presencia implica el alma-humana, pues este cuerpo sólo puede desarrollar sus habilidades si el alma se encuentra en el cuerpo; de lo contrario, el cuerpo perderá la fuerza y el apetito, no podrá trabajar, estará enfermo, quedará exánime, lo cual equivale a decir en posición horizontal, esto es, lo contrario de la posición bípeda y erguida que define la humanidad del cuerpo-presencia de los humanos. En cambio, el alma-humana no implica —esto es, no requiere ser complementada por - el cuerpo-presencia, como sucede por ejemplo durante el sueño, cuando el alma divaga separada del cuerpo; y, de hecho, no es ésta la que sufre como resultado de la separación, sino el último. Por su parte, el alma-espíritu no necesita el cuerpo-carne, pero este sí necesita ser animado por un principio espiritual; y en este sentido, no parece casual que en la mitología mesoamericana sea tan común que las formas animales se originen en las partes carnales de un cuerpo humano despedazado. ${ }^{24}$ En fin, para decirlo en palabras de Merlau-Ponty (1970), el cuerpo posee profundidad ontológica; para poder llegar a ser, necesita de la no forma y la no substancia, lo invisible y lo impalpable.

\section{Conclusión}

¿No estaré exagerando al hablar de dos cuerpos indígenas, cuando podría decirse simplemente que se trata de dos maneras distintas de hablar de lo que en realidad no es sino una misma cosa? Sin embargo, en el caso maya-tzeltal no se trata simplemente de una metáfora —a diferencia, por ejemplo, del pensamiento político medieval inglés, en el cual "Los dos cuerpos del rey" representaban un lenguaje alegórico (Kantorowicz, 1957: 21)—. El empleo de dos términos

\footnotetext{
${ }^{24}$ De acuerdo con Ronald Schleifer, esta cuarta posición es a menudo enigmática, como "la apertura a una red cada vez mayor de zonas de enredo (entanglement)" (1987: 123).
} 
diferentes para referirse a aquello que en las lenguas europeas denominamos sin más “cuerpo humano”, sugiere que la distinción léxica implica también una distinción conceptual. En tzeltal, los vocablos bak'etal y winkilel poseen significados distintos, se emplean en circunstancias diferentes, y uno no está incluido en el otro. Si admitimos que la experiencia física está moldeada por el contexto linguiístico —que el lenguaje no se limita a ser una función de la expresiónpodemos suponer que este produce un cierto significado perceptual. ${ }^{25}$

Curiosamente, encontramos una distinción similar en la etnografía melanesia. Los paiela de las Tierras Altas de Papúa y Nueva Guinea, explica Aletta Biersack, reconocen un cuerpo activo o "cuerpo trabajador", un "cuerpo-sujeto", cuyo movimiento y funcionamiento son "voluntarios e intencionales", y un segundo, "el cuerpo estacionario", que funciona de manera involuntaria, "sin sujeto", "ni inteligente ni inteligible". La vitalidad del primero es diurna, cuando el Sol permite el trabajo; la del segundo, que no piensa, habla o actúa, sino simplemente crece y consume, es nocturna, asociada con la Luna (1996: 93). La diferencia entre un cuerpo pasivo y otro activo — pese a que, como observa Lambek (1998: 111), la autora no proporciona términos léxicos específicos para el contraste- recuerda inevitablemente la distinción que he venido trazando aquí.

Sin embargo, la cuestión, evidentemente, no reside en determinar si se trata de dos cuerpos o uno, como reconocer a lo que apunta esta distinción: la tendencia más general indígena a disociar - a no reunir, si se prefiere- los aspectos somáticos de los aspectos fenoménicos del cuerpo humano. Una persona compuesta tanto por dos dimensiones corporales como por dos dimensiones anímicas nos induce a reemplazar la oposición binaria simple cuerpo/alma por un modelo relacional que, sin perder el principio binario, admita la "coexistencia de los contrarios" (Greimas, 1989: 147). No deseo sugerir con esto que la oposición cuerpo/alma no sea relevante. Una distinción de este tipo, por imprecisa que sea, parece elemental (Lambek, 1998; Descola, 2005); y en el caso particular de los tzeltales (Pitarch, 1996) suministra una polaridad fundamental en términos del "nosotros" (el cuerpo) y los "otros en nosotros" (almas que son espíritus, muertos, europeos, acontecimientos del pasado, etc.). Es más, dado que todo sistema semiótico es jerárquico (Greimas y Courtés, 1991), las relaciones de contrariedad que se establecen entre los dos cuerpos y entre las dos almas contraen entre ellas a su vez una relación de contradicción, mientras que las dos relaciones

\footnotetext{
${ }^{25}$ Me doy cuenta que, para evitar hablar de dos cuerpos, lo cual no deja de ser algo antiintuitivo, podríamos llamar al bak'etal simplemente “cuerpo" y traducir swinkilel como "persona”. Ahora bien, la persona europea parece abarcar un campo considerablemente distinto que el cuerpo-presencia indígena: incluye, por ejemplo, aspectos no estrictamente corporales como las almas (por no hablar de la "persona legal"), y se recordará que la persona cristiana (Mauss, 1971) es en buena medida una entidad metafísica (las tres personas de la Santísima Trinidad, etc.). En cambio, el cuerpo-presencia indígena se caracteriza por su fisicalidad. Algunas traducciones de los diccionarios indígenas insisten en este carácter; por ejemplo el huasteco de Tapia Zenteno (1985): Inic: "hombre"; Inictal: "el cuerpo"; Inictalab: "persona, su corporeidad".
} 
de complementariedad entre los cuerpos y "sus" almas establecen entre sí una relación de contrariedad. Dicho de otro modo, en términos jerárquicos cuerpo y alma se contradicen, forma y materia se presuponen mutuamente.

Pero es cierto que un modelo cuaternario de la persona mesoamericana viene a matizar y complicar la categorización "tajante” de la lógica binaria. Pienso en la iluminadora formulación de Viveiros de Castro según la cual, contrariamente a la lógica europea, en las culturas amerindias el alma es el elemento que integra a seres humanos y animales y otros seres en una misma categoría, mientras el cuerpo es aquello que diferencia a los humanos de los demás seres de la naturaleza (2002a: 387-388). Por lo que respecta al caso tzeltal, este principio que, como hemos visto, en términos "jerárquicos" resulta correcto, debe ser sin embargo matizado para reconocer cómo, aunque sea de manera "incluida”, ambas dimensiones de la persona — corporal y espiritual— poseen una función tanto integradora como diferenciadora. Y esta función cambia según se trate ora de animales del mundo ordinario, ora de espíritus y demás seres del estado sagrado. Así, si el cuerpo-presencia diferencia a los humanos tanto de los animales como de los espíritus, el cuerpo-carnal integra a los humanos con los animales y diferencia a los humanos de los espíritus. Por su parte, lo que he llamado almahumana diferencia a los humanos de los animales, y asocia a los humanos con los espíritus, mientras el alma-espíritu integra a los humanos tanto con los animales como con los espíritus. ${ }^{26}$

En consecuencia, el ser humano indígena - en una especie de escalada de la noción de diferencia interna- contiene en sí mismo las relaciones potenciales de conjunción y disyunción con el resto de los seres. La persona se encuentra internamente constituida por sus relaciones externas con los no humanos, tal y como estos son definidos y distinguidos entre sí desde una perspectiva indígena. Esto es lo que, si entiendo bien, Wagner (1991: 163) llama una "persona fractal": "Una entidad con la relacionalidad integralmente implicada" ("an entity with relationship integrally implied”).

${ }^{26}$ En una perspectiva mesoamericana, podría no resultar tan clara la inversión simétrica que Viveiros de Castro (2002a) encuentra entre el modo europeo e indígena de reconocer la común humanidad. Los europeos se interesarían por saber si los indios tienen alma, pero no un alma genérica sino específicamente racional; los indios, por saber si los europeos tienen un cuerpo humano, pero no un cuerpo fenoménico, sino un cuerpo carnal, dado que lo que en definitiva quieren saber los indios - como indica la anécdota antillana citada por Levi-Strauss- es si los cuerpos europeos son putrescibles o no. En otras palabras, los europeos se preocupan por saber si los indios son animales; los indios, si los europeos son espíritus (divinidades, muertos, etc.). 


\section{BIBLIOGRAFÍA}

Barthes, Roland

1982 "Lesson in Writing", A Barthes Reader, pp. 293-311, S. Sontag (ed.). Nueva York: The Noonday Press.

Bartolomé, Miguel A. y Alicia Barabas

1996 Tierra de la palabra: historia y etnografía de los chatinos de Oaxaca. México: Instituto Nacional de Antropología e Historia.

Barrera Vázquez, Alfredo et al.

1980 Diccionario Maya Cordemex; maya-español, español-maya. Mérida: Cordemex.

Berlin, Brent

1978 Tzeltal Numeral Classifiers. La Haya: Mouton.

Berlin, Elois Ann y Brent Berlin

1996 Medical Ethonobiology of the Highland Maya of Chiapas. The gastrointestinal Diseases. Nueva Jersey: Princeton University Press.

Biersack, Alleta

1996 "Word Made Flesh: Religion, the Economy, and the Body in the Papua New Guinea Highlands”, History of Religions, 36 (2): 85-111. Chicago: The University of Chicago Press.

Bunzel, Ruth

1981 Chichicastenango. Guatemala: Seminario de Integración Guatemalteca.

Chamoux, Marie-Noèlle

1996 “'L' humain' et le 'non-humain' dans un dialecte nahuatl contemporain”, Amerindia 21: 27-45. París: Centre National de la Recherche Scientifique, Centre d'Etudes des Langues Indigènes d'Amerique.

Crocker, Christopher

1992 "El hombre-mono con ojos de metal. Maneras bororo de apodar a los otros", De palabra y obra en el Nuevo Mundo, vol. 1, Imágenes interétnicas., pp. 67-85, M. León-Portilla et al. (eds.). Madrid: Siglo XXI.

Descola, Philippe

2005 Par-delà nature et culture. París: Gallimard.

Domingo de Ara, fray

1986 Vocabulario de lengua tzeldal según el orden de Copanabastla, edición de Ma-

[1571] rio H. Ruz. México: Universidad Nacional Autónoma de México.

Elkins, James

1986 "Two conceptions of the Human Form: Bernard Siegfried Albinus and Andreas Vesalius", Artibus et Historiae, 14: 91-107. Bolonia: Istituto per le Ricerche di Storia dell'Arte. 
Fernández Juárez, Gerardo

2000 "El culto al 'Tío' en las minas bolivianas”, Cuadernos Hispanoamericanos, 597:

25-32. Madrid: Asociación de Revistas Culturales de España (A.R.C.E).

Galinier, Jacques

1990 La mitad del mundo. Cuerpo y cosmos en los rituales otomíes. México: Universidad Nacional Autónoma de México.

Gossen, Gary H.

1974 Chamulas in the World of the Sun. Time and Space in a Maya Oral Tradition. Prospect Heights, Illinois: Waveland Press.

Graulich, Michael

1997 "Chasse et sacrifice humain chez les Aztèques", Bulletin des Séances de l'Académie Royale des Sciences d'Outre Mer, 43 (4): 433-446. Bruselas: L'Academie.

Greimas, Algirdas Julius

1989 Del sentido: ensayos semióticos. Madrid: Gredos.

Greimas, Algirdas Julius y Joseph Courtés

1991 Semiótica. Diccionario razonado de la teoría del lenguaje. Madrid: Gredos.

Hugh-Jones, Stephen

1979 The Palm and the Pleiades. Initiation and Cosmology in North-West Amazonia. Cambridge: Cambridge University Press.

Hultkrantz, Akë

1953 Conceptions of the Soul Among North American Indians: a Study in Religious Ethnology. Estocolmo: Ethnographical Museum.

Ingold, Tim

1991 The Perception of the Environment. Essays in Livelihood, Dwelling and Skill. Londres: Routledge.

Kantorowicz, Ernst

1957 The King's two Bodies. A Study in Mediaeval Political Theology. Princeton: Princeton University Press.

Kaufman, Terence

2003 A Preliminary Mayan Etymological Dictionary. Davies, California: Foundation for the Advancement of Mesoamerican Studies.

Lambeck, Michael

1998 "Body and Mind in Mind, Body and Mind in Body: Some Anthropological Interventions in a Long Conversation", Bodies and Persons: Comparative Perspectives from Africa and Melanesia, pp. 103-122, M. Lambeck y A. Strathern (eds.). Cambridge: Cambridge University Press. 
Laughlin, Robert M.

1975 The Great Tzotzil Dictionary of San Lorenzo Zinacantán. Washington D. C.: Smithsonian Institution Press.

León, Lourdes de

1992 "Body parts and location in Tzotzil: a case of grammaticalization", Space in Mesoamerican Languages, pp. 570-590, L. de León y S. C. Levinson (eds.). Berlín: Akademie Verlag.

Levi-Strauss, Claude

1972 Mitológicas II. De la miel a las cenizas. México: Fondo de Cultura Económica.

Levinson, Stephen C.

1994 "Vision, Shape and Linguistic Description: Tzeltal Body-part Terminology and Object Description", Linguistics, 32: 791-855. Nimega: Holanda.

López Austin, Alfredo

1980 Cuerpo humano e ideología. Las concepciones de los antiguos náhuas. México: Universidad Nacional Autónoma de México.

Lupo, Alessandro

2009 "Concepciones nahuas de la persona", Estudios en homenaje a Mercedes Gayosso y Navarrete, pp. 515-534, J. L. Cuevas Gayosso (ed.). México: Universidad Veracruzana.

Mauss, Marcel

1971 "Sobre una categoría del espíritu humano: la noción de persona y la noción del ‘yo'”, Mauss, Sociología y Antropología, pp. 309-337. Madrid: Tecnos.

Mendelson, E. Michael

1958 "A Guatemalan Sacred Bundle", Man, 58: 89-90. Londres.

1963 Los escándalos de Max Simón. Guatemala: Seminario de Integración Social Guatemalteca.

Merleau-Ponty, Maurice

$1970 \quad$ Lo visible y lo invisible. Barcelona: Seix Barral.

Moliner, María

1967 Diccionario de uso del español. Madrid: Gredos. 2 vols.

Moreno, Martha

2011 "Cuerpo, género y sexualidad en las mujeres indígenas de Chiapas". Tesis de doctorado. Madrid: Universidad Complutense de Madrid.

Nájera, Martha Ilia

2000 El umbral hacia la vida. México: Universidad Nacional Autónoma de México.

Nash, June

1979 We Eat the Mines and the Mines Eat Us. Nueva York: Columbia University Press. 
Neurath, Johannes

2008 "Alteridad constituyente y relaciones de tránsito en el ritual huichol: iniciación, anti-iniciación y alianza”, Cuicuilco 15 (42): 29-45. México: Escuela Nacional de Antropología e Historia.

Olavarria, María Eugenia, Cristina Aguilar y Erica Merino

2009 El cuerpo flor. Etnografía de una noción yoeme. México: Universidad Autónoma Metropolitana.

Pedersen, Morten A.

2001 "Totemism, Animism and North Asian Indigenous Ontologies", Journal of the Royal Anthropological Institute, 7 (3): 411-427.

Platt, Tristan

2001 "El feto agresivo. Parto, formación de la persona y mito-historia en los Andes", Anuario de Estudios Hispanoamericanos, 58 (2): 633-678. Sevilla: Escuela de Estudios Hispano-Americanos.

Pitarch, Pedro

1996 Ch’ulel. Una etnografía de las almas tzeltales. México: Fondo de Cultura Económica.

2000 "Conjeturas sobre la identidad de los santos tzeltales", Journal de la Societé des Americanistes, 86: 129-148. París.

2008 "The Labyrinth of Translation: A Tzeltal Version of the Universal Declaration of Human Rights", Human Rights in the Maya Region: Global Politics, Moral Engagements, and Cultural Contentions, pp. 76-98, P. Pitarch y S. Speed (eds.). Durham, Carolina del Norte: Duke University Press.

2010 The Jaguar and the Priest. An Ethnography of Tzeltal Souls. Austin: University of Texas Press.

Romero López, Laura E.

2006 Cosmovisión, cuerpo y enfermedad. El espanto entre los nahuas de Tlatoltepec de Díaz, Puebla. México: Instituto Nacional de Antropología e Historia.

Ruz, Mario H.

1996 "El cuerpo: miradas etnológicas", Para comprender la subjetividad. Investigación cualitativa en salud reproductiva y sexualidad, pp. 89-136, I. Szasz y S. Leonor (eds.). México: El Colegio de México.

Schleifer, Ronald

1987 A. J. Greimas and the Nature of Meaning: Linguistics, Semiotics and Discourse Theory. Beckenham, Reino Unido: Croom Helm.

Stross, Brian

1976 “Tzeltal Anatomic Terminology: Semantic Processes”, Mayan Linguistics, M. McClaren (ed.). Los Ángeles: University of California Los Angeles.

Surrallés, Alexandre

2003 Au coeur du sens. Perception, affectivité, action chez les Candoshi. París: Centre National de la Recherche Scientifique Editions. 
Tapia Zenteno, Carlos

1985 Paradigma apologético y noticia de la lengua huasteca, edición de René Acuña.

México: Universidad Autónoma de Chiapas.

Taylor, Anne Christine

1996 "The soul's body and its states: an amazonian perspective on being human”, Journal of the Royal Anthropological Institute, 2 (1): 201-215. Londres.

1998 "Corps immortel, devoir d'oubli: formes humaines et trajectoires de vie chez les Achuar", La Production du corps, M. Godelier y M. Panoff (eds.). París: Archives Contemporaines.

Taylor, Anne Christine y Eduardo Viveiros de Castro

2006 “Un corps fair de regards”, Qu'est-ce qu'un corps?, pp. 148-199, S. Breton, J.-M. Schaeffer, M. Houseman, A.-C. Taylor y E. Viveiros de Castro (eds.). París: Musée du Quai Branly/Flammarion.

Tedlock, Dennis

1993 Breath on the Mirror: Mythic Voices and Visions of the Living Maya. San Francisco: Harper \& Collins.

Villa-Rojas, Alfonso

1980 "La imagen del cuerpo humano según los mayas de Yucatán”, Anales de Antropología, II Etnología y Lingüística, XVII: 31-46. México: Universidad Nacional Autónoma de México, Instituto de Investigaciones Antropológicas.

Viveiros de Castro, Eduardo

2002a "Perspectivismo e multinaturalismo na América indígena", A Inconstância da alma selvagem, pp. 345-399, E. Viveiros de Castro (ed.). São Paulo: Cosac \& Naify.

2002b "Atualizaçao e contra-efectuaçao do virtual: o processo do parentesco", $A$ Inconstância da alma selvagem, pp. 401-456, E. Viveiros de Castro (ed.). Sao Paulo: Cosac \& Naify.

2009 Métaphysiques cannibales. París: Presses Universitaires de France.

Wagner, Roy

1981 The Invention of Culture. Chicago: Chicago University Press.

1991 "The Fractal Person", Big Men and Great Men: Personifications of Power in Melanesia, edición de Maurice Godelier \& Marilyn Strathern. Cambridge: Cambridge University Press.

2010 "Foreword", Pedro Pitarch, The Jaguar and the Priest. An Ethnography of Tzeltal Souls. Austin: University of Texas Press.

Willerslev, Rane

2007 Souls Hunters: Hunting, Animism and Personhood among the Siberian Yukaghirs. Berkeley: University of California Press. 